\title{
Economic Model Predictive Control for Hot Water Based Heating Systems in Smart Buildings
}

\author{
M. A. Ahmed Awadelrahman'1, Yi Zong'2, Hongwei Li ${ }^{3}$, Carsten Agert ${ }^{4}$ \\ ${ }^{1}$ Institute of Physics, University of Oldenburg, Oldenburg, Germany \\ ${ }^{2}$ Centre for Electric Power and Energy, Department of Electrical Engineering, Technical University of Denmark, Roskilde, \\ Denmark \\ ${ }^{3}$ Section of Building Energy, Department of Civil Engineering, Technical University of Denmark, Lyngby, Denmark \\ ${ }^{4}$ NEXT ENERGY, EWE Research Centre for Energy Technology at the University of Oldenburg, Oldenburg, Germany \\ Email:yizo@elektro.dtu.dk
}

How to cite this paper: Awadelrahman, M.A.A., Zong, Y., Li, H.W. and Agert, C. (2017) Economic Model Predictive Control for Hot Water Based Heating Systems in Smart Buildings. Energy and Power Engineering, 9, 112-119.

https://doi.org/10.4236/epe.2017.94B014

Received: December 9, 2016

Accepted: March 30, 2017

Published: April 6, 2017

\begin{abstract}
This paper presents a study to optimize the heating energy costs in a residential building with varying electricity price signals based on an Economic Model Predictive Controller (EMPC). The investigated heating system consists of an air source heat pump (ASHP) incorporated with a hot water tank as active Thermal Energy Storage (TES), where two optimization problems are integrated together to optimize both the ASHP electricity consumption and the building heating consumption utilizing a heat dynamic model of the building. The results show that the proposed EMPC can save the energy cost by load shifting compared with some reference cases.
\end{abstract}

\section{Keywords}

Building Energy Management System, Demand Response, Economic Model Predictive Control, Heat Pumps, Smart Buildings, Thermal Energy Storage

\section{Introduction}

Setting a target of $100 \%$ renewable energy including transport sector by 2050 and 50\% of electricity consumption supplied by wind in 2020 in Denmark, under the European 20-20-20 target regarding renewable energy policies [1], provides power systems with new challenges due to renewable energy sources fluctuating nature which calls for additional flexibility on the demand side. In the European Union, buildings are responsible for $40 \%$ of total energy consumption including approximately $20 \%$ absorbed in heating [2], which can be effectively 
used in the demand side management (DSM) strategy as a shiftable load.The electricity prices can reflect surplus or deficiency in electricity supply and also the low prices can indicate the high renewable energy penetration in Denmark.

The EMPC is a validated strategy in designing smart buildings' control and has been studied thoroughly in the recent years. An MPC-based scheduling algorithms developed in [3] for the building energy management system to exploit the thermal mass of the building as well as the non-thermal appliances flexibility to incur energy savings. A pilot study in [4] showed that energy savings and load shifting can be achieved by applying EMPC for electric heaters consumption utilizing a residential building mass as heat storage.

Although the Thermal Energy Storage (TES) is a very potential powerful instrument in DSM programs [5], and the efficiency of the whole system can be extremely enhanced by using heat pumps as energy efficient heating equipment; but this combination has not been studied intensively in the DSM strategies. A study in [6] analyzed heat pump coupled with TES under a DSM strategy designed to flatten the electricity load curve by switching off the heat pump during specific peak hours.

Particularly in this paper we studied a system which consists of an ASHP incorporated with a hot water tank as active TES connected to hot-water radiators utilizing the building mass as passive energy storage. The building model used in this paper is discussed in [4], and the stratification phenomenon is considered in the TES model. Based on the dynamic power price signals and the weather forecast, EMPC optimizes both the ASHP electricity consumption and the building heating consumption; the system's energy consumption is compared with some reference cases.

The rest of this paper is organized as follows: The system models are introduced in Section 2; the EMPC algorithm for the studied system is developed in Section 3; the corresponding results are shown in Section 4. Finally, the conclusion is drawn in Section 5.

\section{Modeling}

The heating units in the building are hot-water radiators distributed among the rooms and fed by hot water via inlet electro-valves which can control the water flow rate. The building model was developed in [4], what-so-called $T_{i} T_{e}$ model as a state space model that considers the building envelope temperature as well as the indoor air temperature.

\subsection{ASHP Model}

The ASHP heat output rate $Q_{h}$ can be calculated by Equation (1) where $P_{e l}$ is the ASHP electric power consumption.

$$
Q_{h}=C O P * P_{e l}
$$

The model considers the air source temperature dependency in a linearized relation. Then the $C O P$ and $Q_{h}$ can be given by Equations (2) and (3), where 
$C O P_{0}, Q_{0}, a_{1}$ and $b_{1}$ are identified according to manufacturer's specifications [7].

$$
\begin{gathered}
C O P=C O P_{0}+a_{1} T_{a} \\
Q_{h}=Q_{0}+b_{1} T_{a}
\end{gathered}
$$

\subsection{TES Model}

Thermal stratification is an important concept when dealing with hot water storage, which results from the density difference between the warm water and the cold water causing the hot water to ascend to the top. Studies as in [8] showed that improving the thermal stratification can significantly improve the system efficiency. The TES model is developed based on the concept illustrated in [9]. Figure 1 shows a stratified tank with $L$ meters height and $N$ layers. The hot water is fed from the production side to the top layer with $\dot{m}_{h p}$ mass flow rate at temperature $T_{h p, o u t}{ }^{\circ} \mathrm{C}$. The heat load is supplied from the top layer with $\dot{m}_{l}$ flow rate of and the return is to the bottom layer to avoid thermal mixing.

The heat balance can be given by Equation (4). Where $m$ is the mass of the hot water; $C_{p}$ is the water thermal capacity, and $T_{w, i}$ is the water temperature in the $i^{\text {th }}$ layer.

$$
m C_{p} \frac{d T_{w, i}}{d t}=\dot{Q}_{h p, i}-\dot{Q}_{\text {load }, i}-\dot{Q}_{\text {loss }, i}+\dot{Q}_{f r e e, i-1, i+1}+\dot{Q}_{f o r, i-1, i+1}
$$

Beside the ASHP heat input $\dot{Q}_{h p, i}$, the load consumption $\dot{Q}_{\text {load }, i}$ and the losses to the environment $\dot{Q}_{\text {loss }, i}$ the term $\dot{Q}_{\text {free }, i-1, i+1}$ represents the amount if heat exchanged in layer $i$ with the surrounding layers $i-1$ and $i+1$ by natural convection and thermal conduction. In the simplest approximation, this can be summarized in effective vertical heat conductivity $\lambda_{\text {eff }}$, and the heat flow between layer $i-1$ and $i$, or from $i$ to $i+1$. The net heat flow for layer $i$ of height $z$ and cross section $A_{q}$ results in the difference of the two heat flows. The effective heat conductivity $\lambda_{\text {eff }}$ can be between $1-1.5 \mathrm{~W} / \mathrm{mK} . \dot{Q}_{\text {free }}$ is calculated by Equation (5). The forced convection is represented by $Q_{f o r, i-1, i+1}$ and can be calculated by Equation (6), where $\dot{m}$ is the mass flow rate.

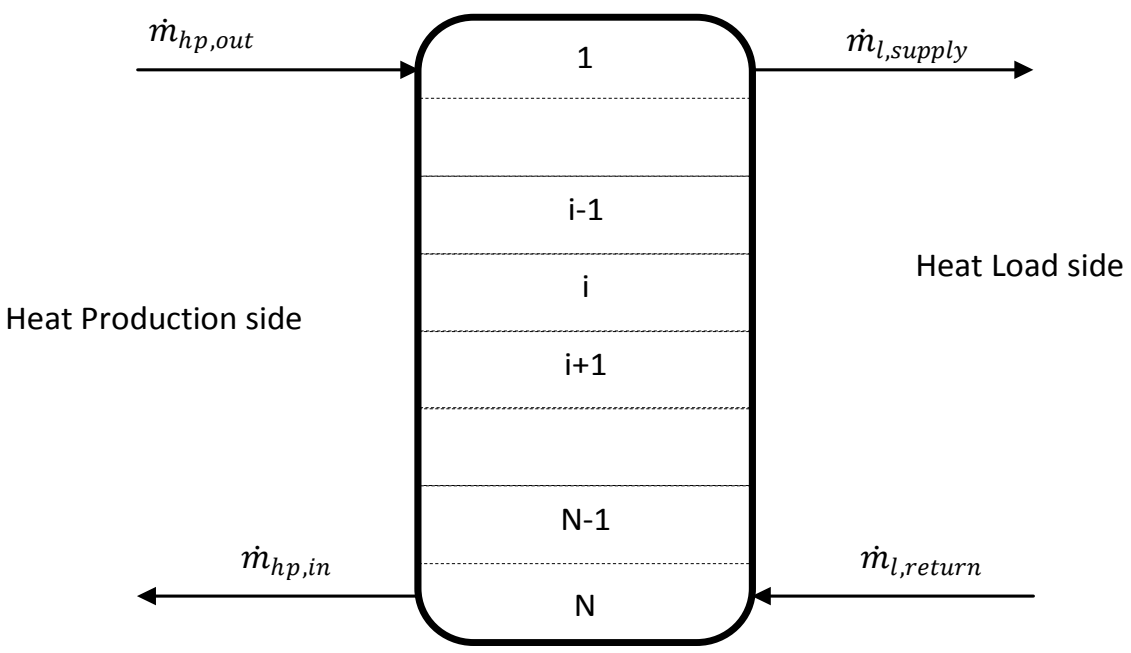

Figure 1. Stratified hot water tank with Nlayers. 


$$
\begin{gathered}
\dot{Q}_{\text {free }}=A_{q} \frac{\lambda_{\text {eff }}}{z}\left(T_{w, i+1}-2 T_{w, i}+T_{w, i-1}\right) \\
\dot{Q}_{\text {for }}=\left(\dot{m}_{i} C_{p}\right)\left(T_{w, i-1}-T_{w, i+1}\right)
\end{gathered}
$$

So $T_{w, i}$ can be calculated downward successively according the Equation (7).

$$
\begin{aligned}
\left(m_{i} C_{p}\right)_{w} \frac{d T_{w, i}}{d t}= & \delta_{i}^{h p}\left(\dot{m}_{h p} C_{p}\right)\left(T_{h p, o u t}-T_{w, i}\right)-\delta_{i}^{l}\left(\dot{m}_{l} C_{p}\right)\left(T_{w, i}-T_{l, \text { return }}\right) \\
& -U_{\text {eff }} A_{i}\left(T_{w, i}-T_{a}\right)+\delta_{i}^{+} \dot{m}_{i} C_{p}\left(T_{w, i-1}-T_{w, i}\right) \\
& +\delta_{i}^{-} \dot{m}_{i+1} C_{p}\left(T_{w, i}-T_{w, i+1}\right)-A_{q} \frac{\lambda_{\text {eff }}}{\mathrm{z}}\left(T_{w, i}-T_{w, i-1}\right)
\end{aligned}
$$

where:

$\dot{m}_{i}=\dot{m}_{h p}-\dot{m}_{l}$, for $i=2, N$ and $\dot{m}_{i}=0$, for $i=1$ and $i=N+1$

$\delta_{i}^{h p}, \delta_{i}^{l}, \delta_{i}^{+}$and $\delta_{i}^{-}$are control parameters as follows:

ASHP is connected to the top layer, and the heat load is returned to the bottom layer:

$$
\delta_{i}^{h p}=\left\{\begin{array}{ccc}
1 & \text { for } & i=1 \\
0 & \text { for } & i \neq 1
\end{array} \quad \delta_{i}^{l}=\left\{\begin{array}{lll}
1 & \text { for } & i=N \\
0 & \text { for } & i \neq N
\end{array}\right.\right.
$$

Energy input from layer $i-1$ to layer $i$; and the energy input from layer $i+1$ to $i$ :

$$
\delta_{i}^{+}=\left\{\begin{array}{lll}
1 & \text { for } & \dot{m}_{i}>0 \\
0 & \text { for } & \dot{m}_{i} \neq 1
\end{array} \quad \delta_{i}^{-}=\left\{\begin{array}{lll}
1 & \text { for } & \dot{m}_{i}<0 \\
0 & \text { for } & \dot{m}_{i} \geq 1
\end{array}\right.\right.
$$

\subsection{Hot-Water Radiator Model}

The hot-water radiator heat transfer rate and the hot water mass flow rate are calculated based on Equations (8) and (9) respectively. The design values are based on the EN 442 [10] and the manufacturer's technical manual. Where $\dot{Q}_{\text {des }}$ is the radiator design heat transfer rate; $T_{\text {sur,des }}$ is the design surface temperature; $T_{i n, \text { des }}$ is the design indoor temperature; $T_{\text {return }}$ is the radiator return temperature; $T_{\text {flow }}$ is the flow temperature, $n$ is the correction factor and $\dot{m}$ is the mass flow rate.

$$
\begin{gathered}
\dot{Q}=\dot{Q}_{\text {des }} *\left[\frac{\frac{1}{2}\left(T_{\text {flow }}+T_{\text {return } n}\right)-T_{\text {in }}}{T_{\text {sur,des }}-T_{\text {in des }}}\right]^{n} \\
\dot{m}=\frac{\dot{Q}}{C_{p}\left(T_{\text {flow }}-T_{\text {return }}\right)}
\end{gathered}
$$

\section{Case Study}

The studied system is shown in Figure 2; the ASHP extracts the heat from the air and supplies the TES with hot water. Upon request, the hot water flows through the radiators transferring the required heat by convection to the ambient in each floor in the building, then the cold water flows back to the TES.

In order to utilize both storage capacities, i.e. the building mass and TES, the 


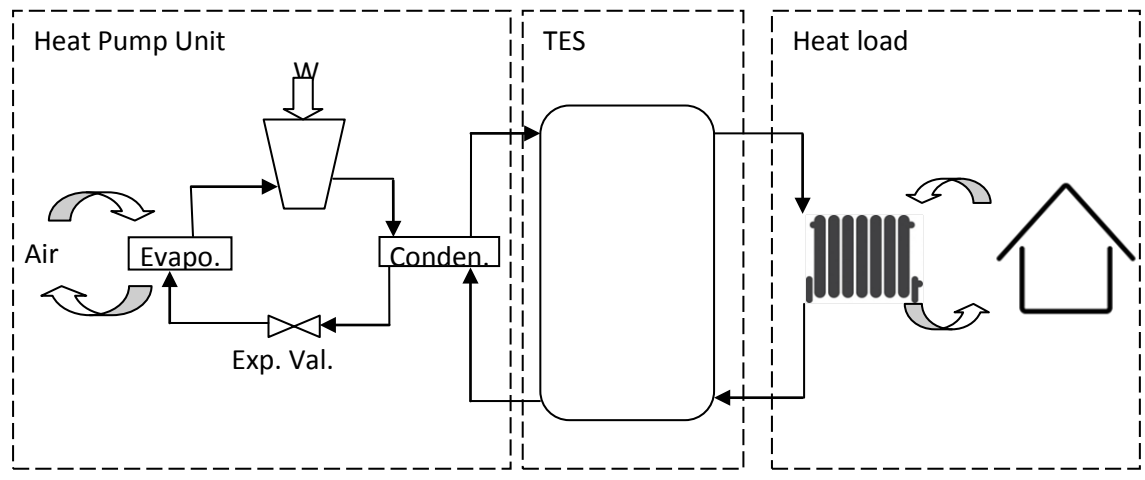

Figure 2. A generic description for the studied system.

EMPC algorithm which is shown in Figure 3 solves two sequential optimization problems for every sampling time within the prediction horizon. The PFH3 algorithm determines the radiators' output to supply the building with the required heat; it is the same as developed in [4]. The second algorithm is to optimize the ASHP electric power consumption to set the TES temperature to the optimal temperature within the operating boundaries.

The objective function of the ASHP optimization is given by Equation (10).

$$
\begin{gathered}
\min J_{P_{e l}}=\sum_{k=0}^{N-1} C_{k}^{\prime} * P_{e l k} \\
\text { s.t. } T_{s, \text { min }, k} \leq g\left(P_{e l}\right) \leq T_{s, \max , k} k=1,2, \ldots(N-1) \\
P_{\min } \leq P_{e l} \leq P_{\max }
\end{gathered}
$$

where: $C$ is the price vector for the prediction horizon $N$ sampled every $k$ period of time. $P_{e l}$ is the ASHP electric consumption, which is the manipulated input within the operational limits $P_{\min }$ and $P_{\max } \cdot g\left(P_{e l}\right)$ is a nonlinear function which represents the temperature of the stored water for the TES top layer, and it is calculated using the TES in Equation (7).

Particularly, $\delta_{1}^{h p}$ is used as the manipulated variable. $T_{s, \min }$ is the minimum stored temperature, in this study the boundary is optimized to meet the demand at a every certain time and not fixed to a constant value; this minimum value is calculated by utilizing the radiator model described in Equation (8) to calculate the optimal $T_{s, \text { min }}$ and it should be sufficient to the maximum required load among the floors. $T_{s, \max }$ is the maximum boundary and set to $100^{\circ} \mathrm{C}$ temperature to keep the water from being evaporated.

\section{Simulation Results}

The system is simulated using day-ahead electricity market price signals and weather data from the local weather station records for 5 days in winter; a reference case is a traditional PID system realized by setting the low and high temperature constraints at the same values to follow the lower comfort band temperature in the building using electric heaters without TES. Also the system is compared to another case in which the ASHP is directly connected to the radiators without the TES, this case is simulated using the PFH3 developed in [4] by utilizing the ASHP model. 


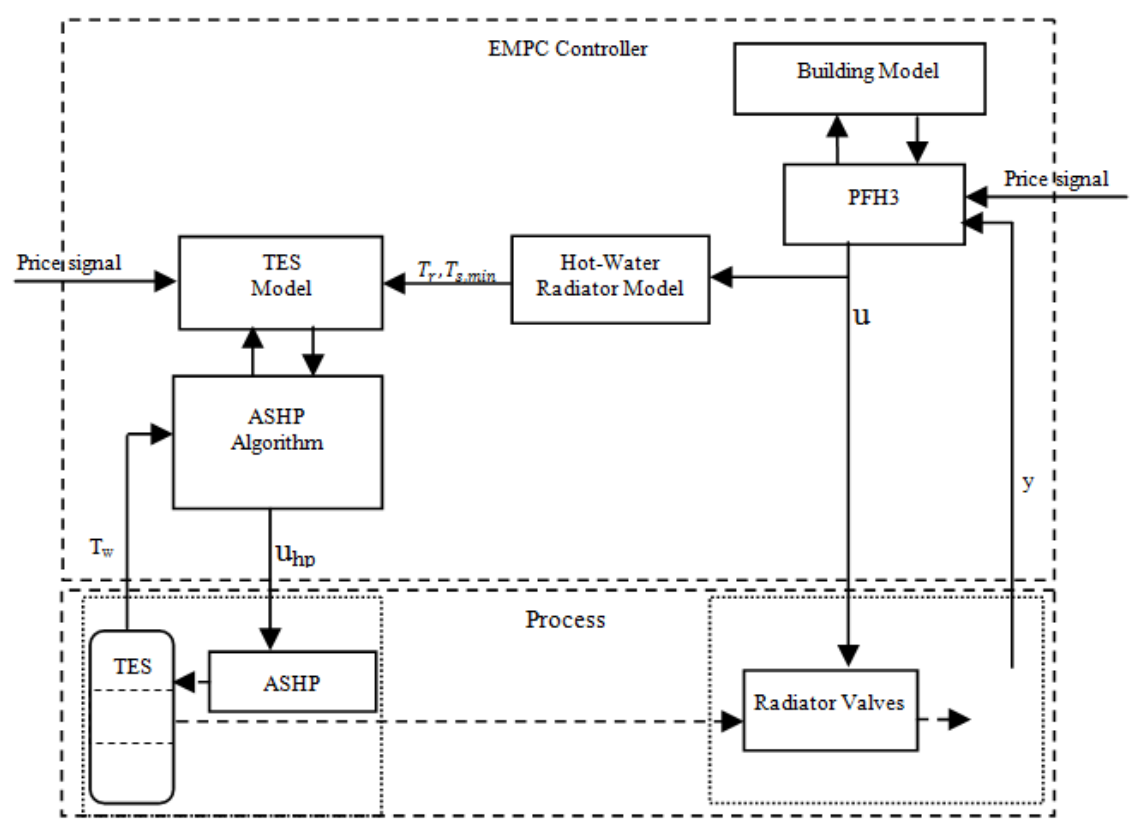

Figure 3. Functional block diagram for EMPC system.

Figure 4 shows the radiators optimal power consumption, the price signal (bottom plot) and indoor temperature (top plot); it is obvious that the radiators consumption is shifted to the low price periods while the indoor temperature is controlled within the comfort constraints (dotted lines). In Figure 5 the bottom plot shows the ASHP optimal electric power consumption shifted to the low price periods; and the temperature of the top layer in the TES (top plot), the lower red dotted curve is the optimal flow temperature calculated from the optimal heat output resulted from PFH3 for every sample time; we can observe the tank top layer temperature is kept within these varying constraints, even though the maximum temperature in the tank is limited to the ASHP maximum flow temperature $\left(55^{\circ} \mathrm{C}\right)$.

The savings are evaluated based on the reference case (the traditional PID) for 10 days simulation and shown in Table 1. Using the EMPC with electric heaters achieved $4.3 \%$ savings over the traditional PID control which reflects the effectiveness of shifting the loads intelligently to the low price periods. Using ASHP with hot-water radiators; the savings jumped significantly to $73.6 \%$ over the reference case when using ASHP with hot-water radiators because of the ASHP principle of operation. The studied system in this paper; incorporating the TES with the ASHP saved $7.9 \%$ more where the total saving incurred is $81.5 \%$ over the reference case.

\section{Conclusion}

The simulation results of the EMPC algorithms effectively showed a successful shift for the electricity demand based on the price where the power consumption is shifted to the low price periods in the study case while the systems states are kept within the limits. In addition, for households, the monetary value of the 

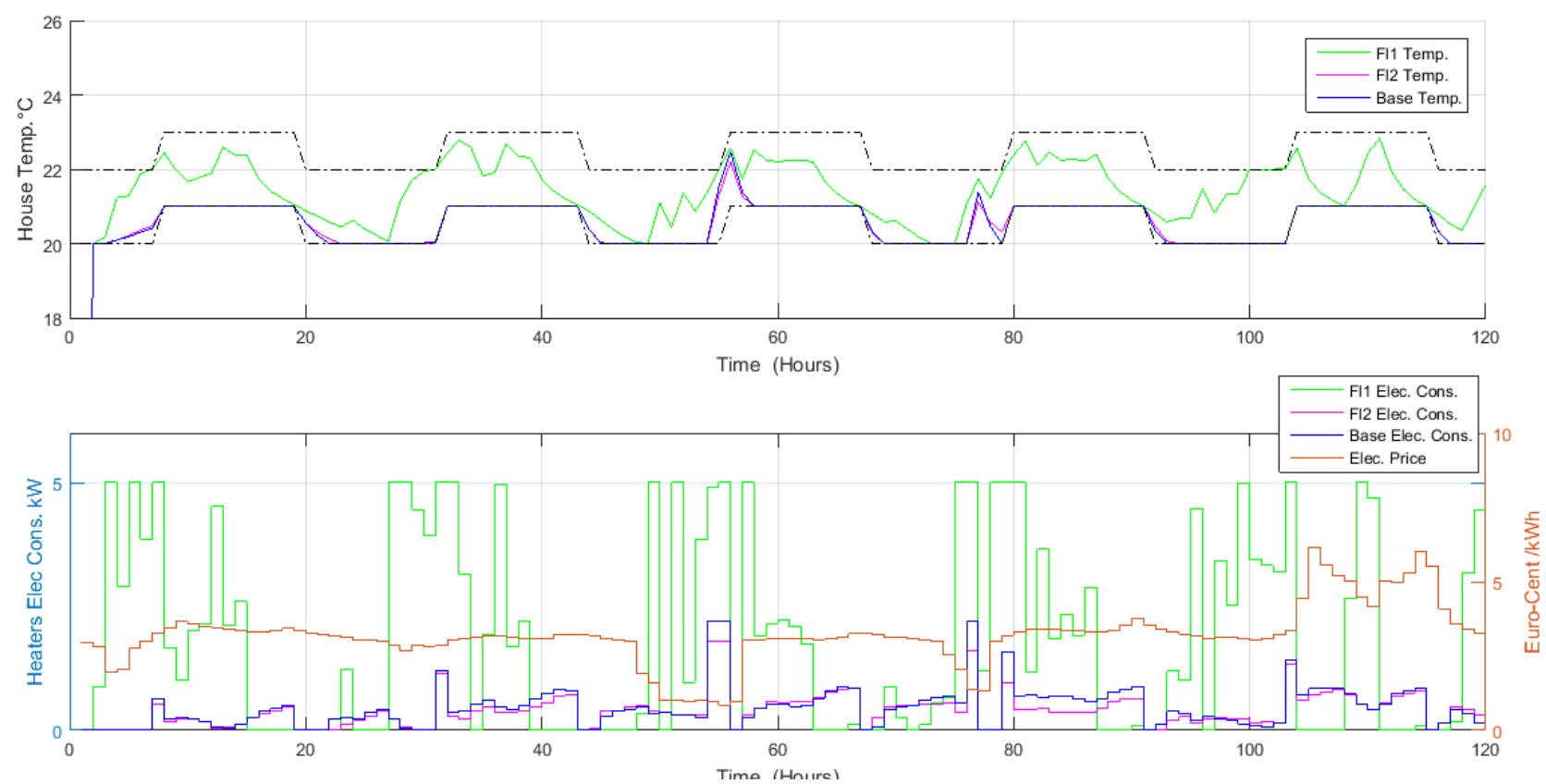

Figure 4. Indoor temperature and optimal heaters' output.
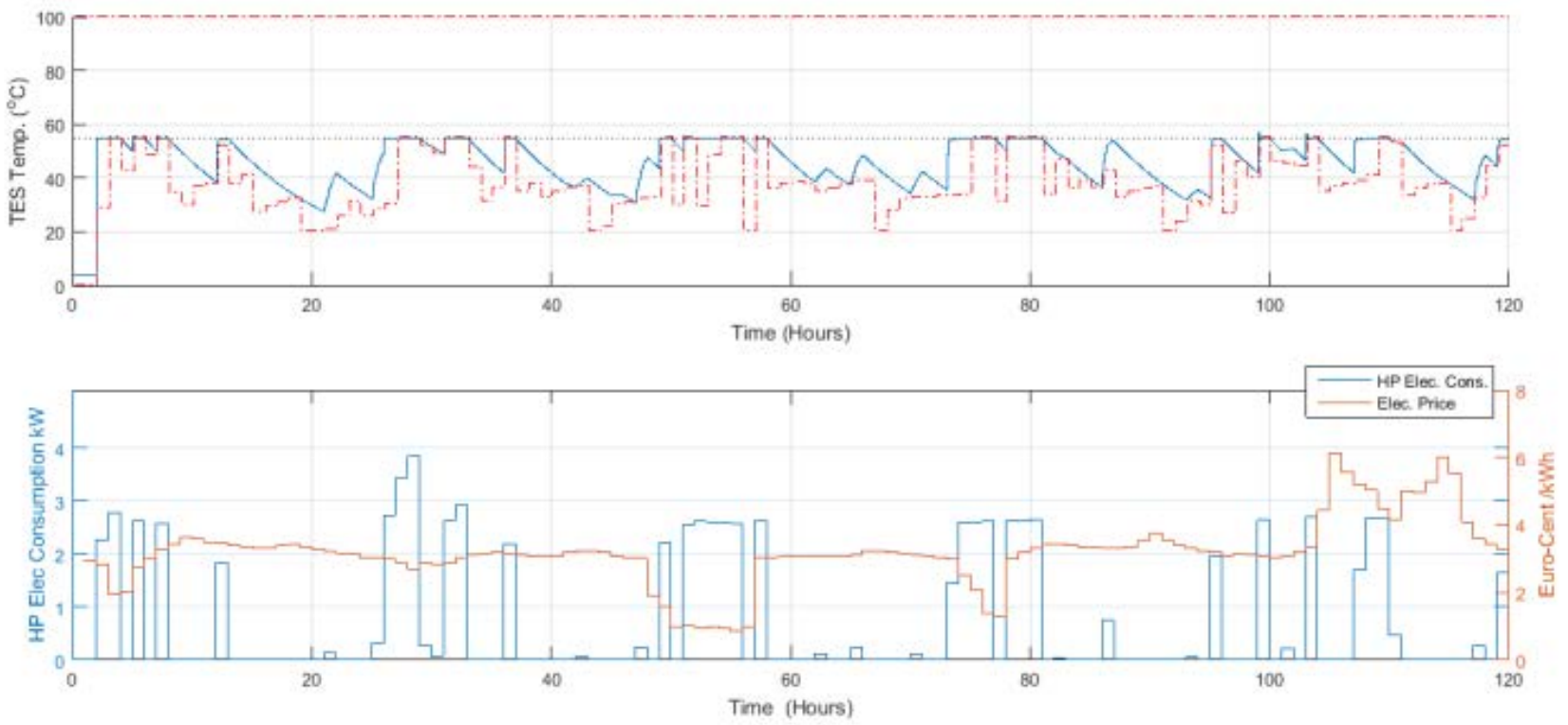

Figure 5. Simulation results for the ASHP and TES.

Table 1. Energy costs for each scenario and savings based on the reference.

\begin{tabular}{ccc}
\hline Scenario & Electricity Costin 10 days (Euro) & Savings \% \\
\hline Reference Case (PID) & $28.00[11]$ & - \\
Case 1: EMPC with Electric Heaters & $26.79[11]$ & $4.3 \%$ \\
Case 2: EMPC with HP & 7.39 & $73.6 \%$ \\
Case 3: EMPC with HP and TES & 5.19 & $81.5 \%$ \\
\hline
\end{tabular}

energy savings is small relative to the complexity of the system and the cost of the equipment, so the payback period for this system could be very long for the 
small buildings with small heat loads; for the future work, a business case could be developed by assuming an agent between the consumer level and the grid operators; this agent can aggregate all the distributed energy sources' flexibility and provide ancillary services to the grid operators.

\section{References}

[1] (2012) Energy Policy in Denmark. DanishEnergy Agency.

[2] E. Union. (1995-2016). European Commission Website, Energy Efficiency, Buildings. https://ec.europa.eu/energy/en/topics/energy-efficiency/buildings

[3] Chen,C., Wang,J.,Heo,Y. and Kishore,S.(2013) MPC-Based Appliance Scheduling for Residential Building Energy Management Controller.IEEE Transactions on Smart Grid, 4.https://doi.org/10.1109/tsg.2013.2265239

[4] Zong,Y.,Böning,G. M., Santos,R. M., You, S.,Hu, J. and Han,X. (2016) Challenges of Implementing Economic Model Predictive Control Strategy for Buildings Interacting with Smart Energy Systems. Applied Thermal Engineering.

[5] Arteconi,A., Hewitt, N. J., and Polonara,F.(2012) State of the Art of Thermal Storage for Demand-Side Management. Applied Energy,Alsevier.

[6] Arteconi,A., Hewitt,N. J., and Polonara,F.(2012) Domestic Demand-Side Management (DSM): Role of Heat Pumps and Thermal Energy Storage (TES) Systems. Applied Thermal Engineering, Elsevier.

[7] V. ViessmannWerkeGmbH\&Co KG, (2012) Heating System and Domestic Ventilation System with Heat Pump Control Unit, Vitotronic 200, type WO1C, Oprating Instructions Vitronic 200.

[8] Lavan,Z. and Thompson,J.(1977) Experimental Study of Thermally Stratified Hot Water Storage Tanks. Solar Energy, 19, 519-524. https://doi.org/10.1016/0038-092X(77)90108-6

[9] Eicker,U.(2003) Solar Technologies for Buildings. John Wiley \& Sons Ltd, Chichester.

[10] BS EN 442-1. (2014) Specification for Radiators and Convectors.

[11] Böning,G. M.(2016) Model Predictive Control (MPC)-based Energy Management of Smart Buildings. MSc, Regenerative Energiesysteme, Fakultät III - Prozesswissenschaften, TechnischeUniversität Berlin. 
Submit or recommend next manuscript to SCIRP and we will provide best service for you:

Accepting pre-submission inquiries through Email, Facebook, LinkedIn, Twitter, etc. A wide selection of journals (inclusive of 9 subjects, more than 200 journals)

Providing 24-hour high-quality service

User-friendly online submission system

Fair and swift peer-review system

Efficient typesetting and proofreading procedure

Display of the result of downloads and visits, as well as the number of cited articles Maximum dissemination of your research work

Submit your manuscript at: http://papersubmission.scirp.org/

Or contact epe@scirp.org 